\title{
Assessing waterbird breeding conditions using an emulator of wetland inundation regime
}

\author{
$\underline{\text { Juan Quijano }}^{1}$, Jose Rodriguez ${ }^{1}$, George Kuczera ${ }^{1}$, Patricia M. Saco ${ }^{1}$, Steven G. Sandi ${ }^{1}$, Rebecca \\ Carlier $^{1}$, Li Wen ${ }^{2}$ and Kelsey McDonough ${ }^{1}$
}

${ }^{1}$ School of Engineering, The University of Newcastle, Callaghan, NSW, Australia

${ }^{2}$ Department of Planning, Industry and Environment, NSW, Australia

juan.quijanobaron@uon.edu.au

\begin{abstract}
Wetlands are essential habitat for waterbirds because they serve as breeding and roosting areas. Waterbirds are useful indicators of wetland ecological health and are essential for the ecosystem function but have been under pressure due to climate and anthropogenic drivers. Colonial waterbird breeding has been found strongly correlated to flooding and inundation regime (flood duration and timing). In this study we applied the WATHNET5 model, a simulation model based on linear programming, to estimate bird breeding events by emulating wetland inundation regimes. The objective is to estimate the occurrence and frequency of colonial waterbird breeding conditions pre/post the construction of a dam on an Australian dryland wetland as an indicator of ecosystem health. We applied the methodology to the Macquarie Marshes from Warren weir Gauge to Carinda Gauge which include the Northern Macquarie Marshes (NMM). The NMM was represented as a network of reservoirs and arcs that emulate the hydrodynamics of the NMM system at a daily time step, which was based on a previously developed 2D hydrodynamic model. The river hydraulics of routing and transmission loss were calibrated with gauge records at two sites from 1986 to 2015 with a Nash Sutcliffe Efficiency of 0.71 . The inundation regime was characterized by simulating the timing, duration and total spring flow arriving at the NMM. The minimum conditions necessary for breeding events were represented by the occasions when inundation exceeded or met minimum inundation regime thresholds. Our model showed that it predicted waterbird breeding conditions with $81 \%$ accuracy using data from nest count campaigns available from 1986 to 2015. Further simulations were carried out for the period from 1913 to 2019, and results indicated that that the frequency of breeding conditions has decreased and the average time between events has increased since the Burrendong dam was constructed. WATHNET5 proved to be a versatile tool to simulate bird breeding conditions and inundation regime, and this methodology can be extended to potentially inform the management of floods and high flow events within the catchment.
\end{abstract}

Keywords: $\quad$ Waterbird breeding, inundation regime, environmental water, WATHNET5 
Quijano et al., Assessing waterbird breeding conditions using an emulator of wetland inundation regime MODSIM 2021

\section{INTRODUCTION}

Wetlands are essential habitat for waterbirds. In wetlands, flooding promotes food production, emergent plants provide shelter for birds and nests, islands offer open space for colony species, and trees serve as roosting sites (Ma et al., 2010). Additionally, permanent and semi-permanent flooded areas offer security to the nests from predators (Hoover, 2006) and are important stop-over points for migratory birds (Runge et al., 2015). Consequently, wetlands are used as both foraging areas and breeding sites for migratory and resident waterbirds. Waterbirds are important component of a wetland, and often used as a bioindicator of ecosystem health (Stolen et al., 2004). They can affect the composition, genetic diversity and structure of ecological communities in the ecosystem through their role as dispersal agent (Amezaga et al., 2002). Recently, wetland restoration success has been measured in terms of waterbird responses (Hagy et al., 2017) and waterbird community composition (Zou et al., 2014). However, waterbirds have been under pressure due to habitat loss and degradation caused by climate change and anthropogenic disruption such as land use changes, dam construction and water resource development (Carney et al., 1999; Davidson, 2014; Reid et al., 2013). Colonial waterbird breeding is greatly correlated to flooding and inundation regime. The size and success of bird breeding can be described in terms of the size of the annual flow (Kingsford et al., 1998), flood duration (Briggs et al., 2001; Cumming et al., 2012) and timing (Rogers et al., 2010). Moreover, wetland plants, which provide breeding habitat and food availability, are also described in terms of inundation regime (Roberts et al., 2011; Webb et al., 2012).

The aim of this paper is to estimate the number of events with suitable conditions for colonial waterbird breeding in an Australian dryland wetland as an indicator of ecosystem health. Estimating the occurrence and frequency of waterbirds breeding events is important to help maintain the critical ecological functions of waterbird and sustain the health and resilience of wetland ecosystems. This could be translated into water management decisions to maintain favourable conditions for the breeding events to happen. Here we used WATHNET5 (Kuczera et al., 2009), a simulation model based on network linear programming with side constraints to estimate conditions for colonial bird breeding events using an emulation of wetland inundation regime. The river was simulated in WATHNET5 using hydraulic routing and conveyance losses, while the wetland as a series of interconnected zones with a reservoir, using volume vs outflow relationships. Computations of the water regime were implemented and minimum requirements for a breeding event were set in order to determine the occurrence and frequency of the events. Validation against recorded data was performed and further simulations were carried out between 1913 and 2019 to determine the effects before and after the construction of a dam.

\section{METHODOLOGY}

\subsection{Study Area}

The Macquarie Marshes are a complex system of streams and wetlands that cover more than 1,300 $\mathrm{km}^{2}$. Around $10 \%$ of the area is designated to and protected as a Ramsar site with international importance. It is located in a semi-arid region of eastern Australia. The Marshes support a wide variety of flora and fauna and are one of the main inland wetlands for the breeding of colonial water birds (Kingsford et al., 1998; OEH, 2012). The Marshes can shelter between 10,000 and 300,000 waterbirds (Kingsford et al., 1995) and support up to 239 permanent or seasonal bird species. The modeling area (Figure 1) for this study was chosen because it includes the Northern Macquarie Marshes (NMM) portion of the Macquarie Marshes Ramsar site and some of the recurrent breeding sites within the Marshes.
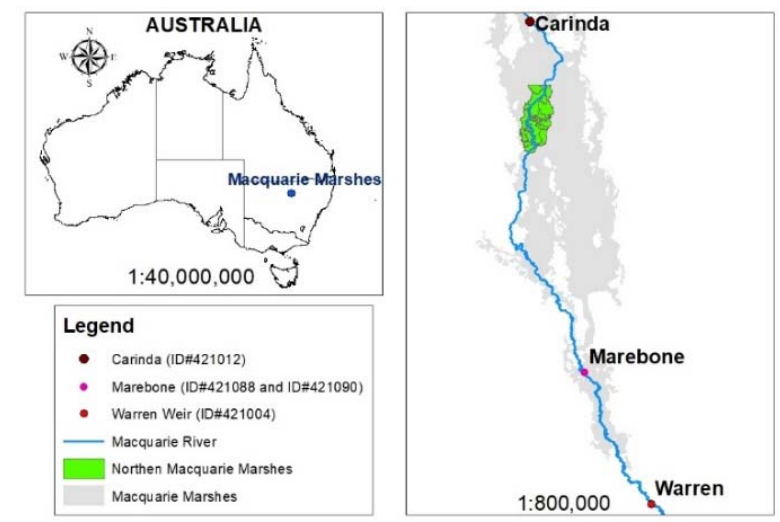

Figure 1. Study area. Left: Location within Australia. Right: Modeling area. 
Quijano et al., Assessing waterbird breeding conditions using an emulator of wetland inundation regime MODSIM 2021

\subsection{Wetland modeling in WATHNET5}

WATHNET5 (Kuczera et al., 2009) is a water resource simulation model that uses a network flow program, in some cases augmented by linear side constraints, to manage water. In this study, we used WATHNET5 to simulate in the Macquarie River from the Warren Weir Gauge to the Carinda Gauge, a reach that includes the Northern Macquarie Marshes (NMM). Flow routing and conveyance losses in the Macquarie River from Warren Weir Gauge to the entrance of the NMM were modeled. The routing uses the Muskingum Cunge method (Cunge, 1969) and the conveyance losses were represented as a four-segment piecewise linear function following the method developed by (Borwell et al., 2016). Conveyance losses and flow routing parameters were calibrated using gauge records.

The NMM was represented as a set of 17 interconnected zones with a reservoir at each zonal outlet. The zones were delineated in such a way that the vegetation within a zone was largely homogeneous using vegetation maps (Bowen et al., 2017; Wilson, 1992) following criteria similar to (Sandi et al., 2020). The connections between the reservoirs of the model domain were determined by analyzing the simulation results using the previously developed quasi-2D Hydrodynamic model of the area (Sandi et al., 2019).

Network flow programs with side constraints use efficient algorithms to minimize the cost of conveying flow through the network, subject to restriction in the capacity of the arcs, mass balance conservation in the nodes and side constraints (Castro et al., 1996). For the NMM part of the model, the network flow program with side constraints can be described using the following notation:

$$
\begin{aligned}
& \text { Minimize } \sum_{i} \sum_{j} c_{i, j} y_{i, j} \\
& \text { subject to (1) } \sum_{j} y_{i, j}-\sum_{l} y_{l, i}=\Delta V_{i} \\
& \text { (2) } 0 \leq y_{i, j} \leq u_{i, j} \\
& \text { (3) } g_{l, i}=\frac{y_{l i}}{V_{i}} \quad \text { when } i \neq j \text { and } l \neq i \\
& \text { Nodal mass balance Capacity constraints Side constraints } \\
& i=1,2, \ldots, N ; \quad j=1, \ldots, N ; \quad l=1,2, \ldots, N
\end{aligned}
$$$$
\text { Eq.1 }
$$

where the first equation represents the objective of minimizing cost (c) of conveying flow (y) from nodes $i$ to nodes $j$ in the network composed by $\mathrm{N}$ nodes. This objective is subject to (1) mass balance at each node, which ensures that the input flows $\left(y_{i, j}\right)$ minus the output flows $\left(y_{l, i}\right)$ are equal to the change in reservoir volume $\left(\Delta V_{i}\right),(2)$ capacity constraints which impose an upper limit $\left(\mathrm{u}_{\mathrm{i}, \mathrm{j}}\right)$ on flows at the arcs, and (3) side constraints where $g_{l, i}$ is the fraction of current reservoir volume that flows out of the reservoir in a day. In our network, the costs are set equal for all the arcs to avoid preferential flow, and the capacity is assigned as infinite, because the outflows from the reservoirs are limited by the side constraints. At each daily time step, WATHNET5 determines the flows and volumes that satisfy the constraints and mass balance.

The side constraints allow the emulation of the inundation regime present in dryland wetlands. Using the approach developed by (Borwell et al., 2015), nonlinear reservoir volume vs outflow relationships were inferred from the results of the quasi-2D hydrodynamic model of the NMM previously implemented by (Sandi et al., 2019). These relationships were then used to formulate dynamically linear side constraints in WATHNET5.

\subsection{Inundation regime in the NMM}

The characterization of the inundation regime requires data of the timing, duration and total spring flow of the water arrived at the NMM. The timing was the calendar month when the inundation starts, while the duration was computed as the consecutive days of inundation. The total spring flow was the summation of flows during September, October and November. These computations were implemented in WATHNET5 using runtime scripts.

\subsection{Simulation of colonial waterbird breeding events in the NMM}

In the Macquarie Marshes, 16 colonial waterbird species have been identified (Kingsford et al., 1995). The minimum conditions for a breeding event were identified as an inundation event that exceeded or met thresholds of timing, duration and total spring flows. Notice that meeting those conditions does not warrant a breeding event but rather expresses the minimum requirements for a breeding event to be possible. The inundation timing and duration were evaluated only in the five areas inside the NMM where colonial water bird breeding has been registered (OEH, 2012). The computation of the total spring flow was recorded in WATHNET5 at the entrance of the NMM and the thresholds were based on the previous studies and are shown 
Quijano et al., Assessing waterbird breeding conditions using an emulator of wetland inundation regime MODSIM 2021

in Table 1. The breeding season normally starts in late winter after large inundation events (Kingsford et al., 2005), takes three to eight months (Brandis et al., 2016; Rogers et al., 2010) and requires a minimum total spring flow in order have the minimum conditions for the event to happen (Bino et al., 2014). The breeding process involves several stages, including nest building, egg laying, incubation and fledging. Vegetation condition can also be a factor affecting the bird breeding, but it was not considered in this study and is left for further work. In order to validate the proficiency of the model to predict conditions for breeding events, results were compared with annual observations (1986-2015).

Table 1. Minimum inundation regime thresholds at Pillicawarrina to have breeding conditions.

\begin{tabular}{|l|l|c|c|}
\cline { 2 - 4 } \multicolumn{1}{c|}{} & Timing & Min Duration (days) & Min Total spring flow (GL) \\
\hline Threshold & July to Nov & 90 & 40 \\
\hline
\end{tabular}

\subsection{Model inputs and experiments}

Only input flows and irrigation demands are necessary to run WATHNET5. Daily flows at Warren Weir Gauge (ID\# 421004) from 1913 to 2019, obtained from the WaterNSW continuous water monitoring network (https://realtimedata.waternsw.com.au/), were used as inputs. Irrigation demands for the same period were obtained from the outputs of the Integrated Quality and Quantity Model (IQQM), a hydrological model developed for the Macquarie River (Wen et al., 2013). Notice that the irrigation demands are a gross estimation and have been used in the absence of more detailed information.

The hydraulic components of WATHNET5 were calibrated with gauge records from 1986 to 2015 . Two sites were selected to calibrate the routing and conveyance losses: Marebone (ID\# 421090 and ID\# 421088) ${ }^{1}$ and Carinda (ID\#421012). Marebone accounts for the Macquarie River flows at the entrance of the main inundation areas within the Macquarie Marshes, while Carinda accounts for the flows after NMM and before the Macquarie River deliver its water to the Barwon River.

The performance of the model to predict conditions for waterbird breeding events was validated against nest count campaigns for large waterbird colonies available from 1986 to 2015 (OEH, 2012). The nests normally contain one to five eggs, of which only $20-50 \%$ survive (McGinness et al., 2020). When nesting was recorded inside the NMM, we assumed breeding also occurred. Ground-based colonial nest counts were performed during the breeding season by the NSW Department of Planning, Industry and Environment (DPIE) or equivalent over time (including NSW National Parks). The Department uses a range of methods to detect colonies including flights and remote cameras. These are augmented by observations (aerial and ground) by others including landholders and universities (Kingsford et al., 2005; Kingsford et al., 1998).

In order to assess how the breeding conditions may have changed over the years, further simulations were carried out between 1913 and 2019 using Warren Weir Gauge records. This period includes natural flows (1913-1967) before Burrendong dam was built (170 km upstream of Warren) and the subsequent regulated flows until 2019. During this period, several periods of large flooding and severe drought (e.g. Millennium Drought 2000-2010) events occurred.

\section{RESULTS}

The WATHNET5 model was implemented and its performance to predict conditions for waterbird breeding events was evaluated. First, the routing and loss components of the model were calibrated by comparing the model results with observations from gauging stations between 1986 and 2019. It is important to note that the simulation of the hydrodynamics within the NMM did not require any calibration. Figure 2 showed that our model results match the observations with a Nash Sutcliffe Efficiency (NSE) of 0.71 and 0.72 for Marebone and Carinda, respectively. The model satisfactorily simulated the wet and dry periods. This provided the foundation to simulate the inundation regime within the NMM and waterbird breeding events.

A validation of the waterbird breeding conditions module was carried out by comparing with recorded breeding events in the NMM. The comparison and confusion matrix are presented in Figure 3. There were a total of 16 breeding events in the 30-year period from 1986 to 2015 . Our model predicted $81 \%$ of the events with three false negatives (1991, 1995 and 2008) and one false positive (2001). Moreover, the model has a substantial agreement with the observations based on a calculated Kappa coefficient of 0.73 (Landis et al., 1977). These results are considered satisfactory, taking into account that a successful waterbird breeding events also depends

\footnotetext{
${ }^{1}$ The Macquarie River has multiple diversions and a network of river channels in the floodplain. In Marebone, the entire flow is represented by Marebone Weir (Gauge No. 421090) and the Marebone Break downstream of the Marebone Regulator (Gauge No. 421088).
} 
Quijano et al., Assessing waterbird breeding conditions using an emulator of wetland inundation regime MODSIM 2021

on complex regional factors (Bino et al., 2015) that cannot be accounted for in the model.

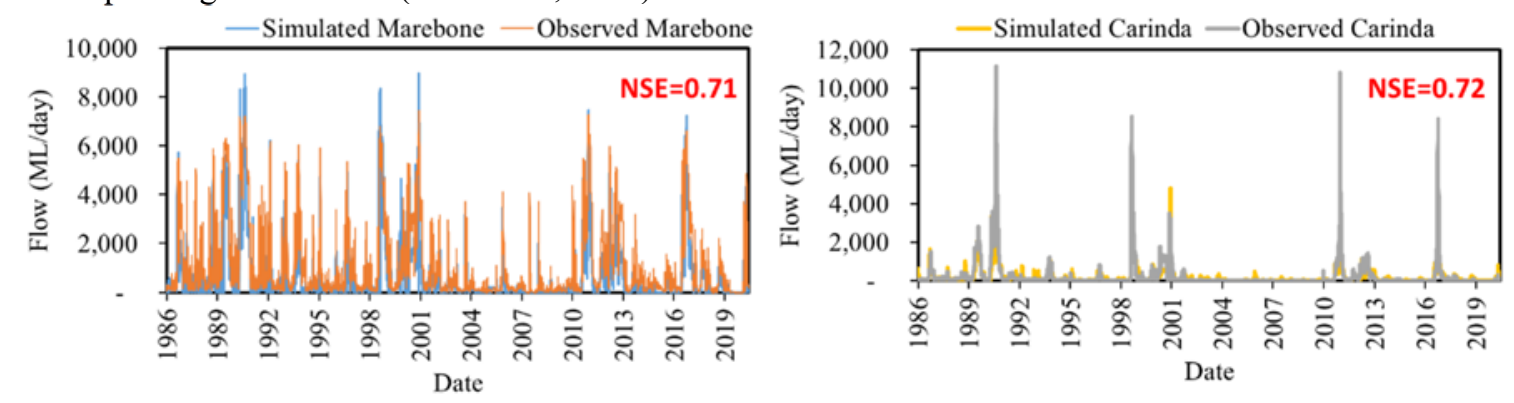

Figure 2. Observed and simulated flows at Marebone (left) and Carinda (right).

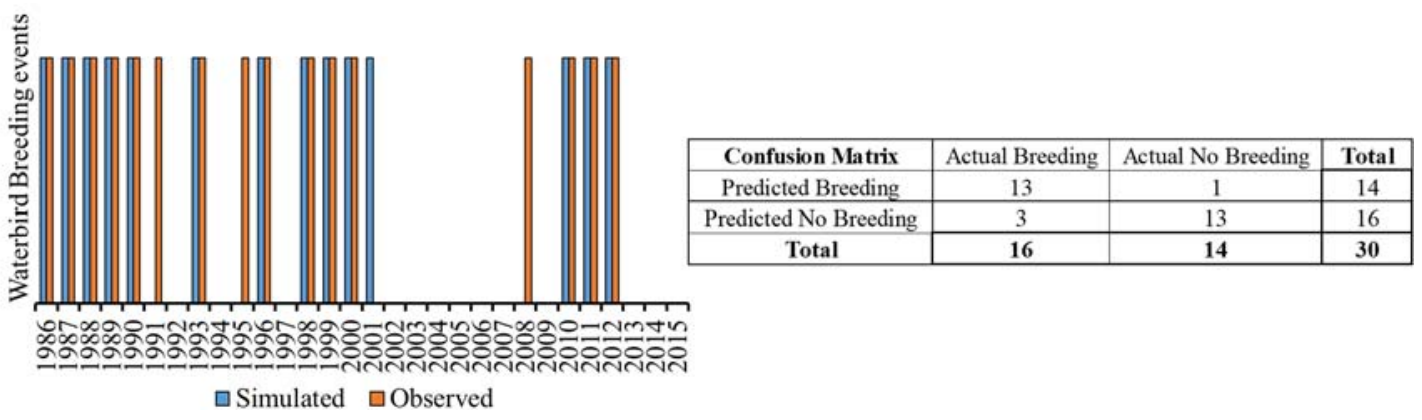

Figure 3. Time series and confusion matrix of the modelled versus registered breeding events.

Once the hydraulics were calibrated and the conditions for breeding events were validated, simulations between 1913 and 2019 were carried out to assess how the breeding events frequency may have changed in the system over time. Our results show that the frequency of breeding events has substantially decreased, and average time between successful events has increased (Figure 4). Between 1913 and 2019, the model predicted a total of 47 breeding events, 29 of which happened before 1967 (the start of operation of Burrendong Dam), and there were only 18 events in the subsequent 53 years. The overall breeding frequency was $44 \%$, decreasing from $53 \%$ to $35 \%$ after 1967 . Additionally, the average years between successful breeding events increased from 2.5 before 1967 to 3.7 afterwards. These results suggested that there has been a decrease in the ecosystem health over the last 50 years.

\begin{tabular}{ccccc} 
Period & Years & Events & Frequency & Av. years between events \\
\hline $1913-1967$ & 55 & 29 & $53 \%$ & 2.5 \\
$1968-2020$ & 52 & 18 & $35 \%$ & 3.7 \\
$1913-2020$ & 107 & 47 & $44 \%$ & 3.2
\end{tabular}

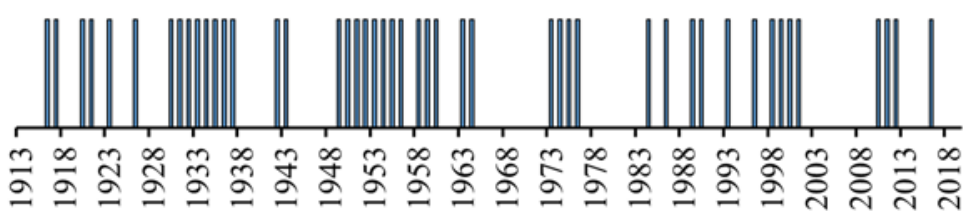

Figure 4. Simulated historical bird breeding events from 1913 to 2019

\section{DISCUSSION}

We found that waterbird breeding conditions can be simulated based on inundation regime in the NMM using WATHNET5. This result is aligned with Kingsford et al. (2005) who found a good correlation between flow flooded area and number of nests for colonially breeding species in the Macquarie Marshes. Similarly, Bino et al. (2014) found a strong linear relationship between flows and probability of bird breeding. Moreover, our results showed a decrease in frequency and increase in time between breeding events since the operation of Burrendong dam, which could indicate a reduction in ecosystem health, a finding consistent with other researchers (Kingsford et al., 1995; Yu et al., 2015). Figure 4 also shows that in the 1960's and first decade of Millennium Drought, the time between events was 8 years, which has been identified as the maximum time between breeding events in order to maintain a viable waterbird population (Brandis et al., 2016). Comparing the simulated breeding conditions (Figure 4) and the different droughts that occurred in Australia (Figure 5), most of the longer periods with no breeding events can be explained (30s-40s, 60s and 80s). Additionally, our 
Quijano et al., Assessing waterbird breeding conditions using an emulator of wetland inundation regime MODSIM 2021

results suggested that the conditions suitable for colonial bird breeding in the NMM have decreased over the last 50 years. This result highlights the importance of making decisions that focus on maintaining or improving ecological services to cope with future climate change (Xi et al., 2021).

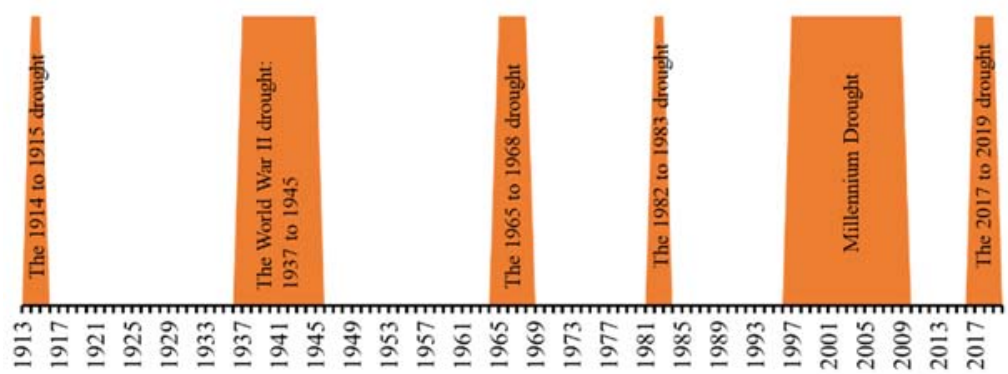

Figure 5. Historical droughts in Australia from 1913. Data obtained from:

http://www.bom.gov.au/climate/drought/knowledge-centre/previous-droughts.shtml

Our model has several limitations that should be considered in future research. First, the irrigation demands are estimations from a previous hydrologic model, which generate high uncertainty in our results. No daily records or irrigation demands were available and better estimations are needed in order to reduce uncertainties. Second, the inundation regime thresholds (Table 1) only provide minimum conditions for bird breeding, but they do not warrant actual breeding. Waterbird breeding depends on regional conditions (Bino et al., 2015) and other factors (e.g. climate, vegetation condition or species abundance) and should be incorporated in future work. Thresholds have been chosen based on data of all observed breeding events, but there maybe some events that are not totally representative of current conditions. Third, we have assumed that spring flows control conditions for bird breeding, which is not always the case. However, the model can be easily generalized to include other triggering flows if more information becomes available. The methodology presented in this study can be adapted and extended to potentially inform the management of floods and high flow events within the catchment and for the analysis of climate change scenarios.

\section{CONCLUSIONS AND RECOMMENDATIONS}

The frequency and occurrence of breeding events is strongly associated with inundation regime, including flooding duration and timing. WATHNET5 is proved to be a versatile tool to simulate inundation regime and conditions for bird breeding events in dryland wetlands. Conditions suitable for bird breeding in the NMM have been decreasing over the last 50 years and management measures to maintain the ecosystem services in NMM are required, especially in the context of climate change. Our approach can be extended to other areas to assess the ecosystem health or investigate the possible effects of climate change and anthropogenic alterations.

\section{ACKNOWLEDGEMENTS}

We acknowledge support from the Australian Research Council through grant DP1701530 and information provided by the NSW Department of Planning, Industry and the Environment.

\section{REFERENCES}

Amezaga, J., Santamaría, L., \& Green, A. J. (2002). Biotic wetland connectivity—supporting a new approach for wetland policy. Acta oecologica, 23(3), 213-222.

Bino, G., Kingsford, R. T., \& Porter, J. (2015). Prioritizing Wetlands for Waterbirds in a Boom and Bust System: Waterbird Refugia and Breeding in the Murray-Darling Basin. PLOS ONE, 10(7), e0132682. doi:10.1371/journal.pone. 0132682

Bino, G., Steinfeld, C., \& Kingsford, R. T. (2014). Maximizing colonial waterbirds' breeding events using identified ecological thresholds and environmental flow management. Ecological Applications, 24(1), 142-157. doi:https://doi.org/10.1890/13-0202.1

Borwell, R., Kuczera, G., Rodriguez, J. F., et al. (2016). Using Calibation Strategies to Emulate a Complex River Basin Model with a Simplified Fit-For-Purpose Model. Paper presented at the Hydrology and Water Resources Symposium, Queenstown, New Zealand.

Borwell, R., Wen, L., J.F, R., et al. (2015). Emulating Macquarie Marshes Hydrodynamics using River Basin Simulation Based on Network Flow Programming. Paper presented at the Hydrology and Water Resources Symposium, Hobart, Australia.

Bowen, S., \& Simpson, S. (2017). Changes in extent and condition of the vegetation communities of the Macquarie Marshes floodplain 1991-2008-2013. New South Wales Department of Environment, Climate Change and Water, Sydney, NSW, Australia. 
Quijano et al., Assessing waterbird breeding conditions using an emulator of wetland inundation regime MODSIM 2021

Brandis, K., \& Bino, G. (2016). A review of the relationships between flow and waterbird ecology in the CondamineBalonneand Barwon-Darling River Systems. Retrieved from Australia:

Briggs, S. V., Lawler, W. G., \& Thornton, S. A. (2001). Relationships Between Hydrological Control of River Red Gum Wetlands and Waterbird Breeding. Emu, 97(1), 31-42. doi:https://doi.org/10.1071/MU97003

Carney, K. M., \& Sydeman, W. J. (1999). A Review of Human Disturbance Effects on Nesting Colonial Waterbirds. Waterbirds: The International Journal of Waterbird Biology, 22(1), 68-79. doi:10.2307/1521995

Castro, J., \& Nabona, N. (1996). Primal-dual interior point method for multicommodity network flows with side constraints and comparison with alternative methods. In System Modelling and Optimization (pp. 451-458): Springer.

Cumming, G. S., Paxton, M., King, J., et al. (2012). Foraging guild membership explains variation in waterbird responses to the hydrological regime of an arid-region flood-pulse river in Namibia. Freshwater Biology, 57(6), 1202-1213. doi:https://doi.org/10.1111/j.1365-2427.2012.02789.x

Cunge, J. (1969). On the subject of a flood propagation computation method (Musklngum method). Journal of Hydraulic Research, 7(2), 205-230.

Davidson, N. C. (2014). How much wetland has the world lost? Long-term and recent trends in global wetland area. Marine and Freshwater Research, 65(10), 934-941.

Hagy, H. M., Hine, C. S., Horath, M. M., et al. (2017). Waterbird response indicates floodplain wetland restoration. Hydrobiologia, 804(1), 119-137. doi:10.1007/s10750-016-3004-3

Hoover, J. P. (2006). Water depth influences nest predation for a wetland-dependent bird in fragmented bottomland forests. Biological Conservation, 127(1), 37-45.

Kingsford, R. T., \& Auld, K. M. (2005). Waterbird breeding and environmental flow management in the Macquarie Marshes, arid Australia. River Research and Applications, 21(2-3), 187-200. doi:10.1002/rra.840

Kingsford, R. T., \& Johnson, W. (1998). Impact of Water Diversions on Colonially-Nesting Waterbirds in the Macquarie Marshes of Arid Australia. Colonial Waterbirds, 21(2), 159-170. doi:10.2307/1521903

Kingsford, R. T., \& Thomas, R. F. (1995). The Macquarie Marshes in Arid Australia and their waterbirds: A 50-year history of decline. Environmental Management, 19(6), 867-878. doi:10.1007/BF02471938

Kuczera, G., Cui, L., Gilmore, R., et al. (2009). Addressing the shortcomings of water resource simulation models based on network linear programming. Paper presented at the 32nd Hydrology and Water Resources Symposium (H2009). Newcastle, Australia Engineers Australia/Causal Productions.

Ma, Z., Cai, Y., Li, B., et al. (2010). Managing wetland habitats for waterbirds: an international perspective. Wetlands, 30(1), 15-27.

McGinness, H., Brandis, K., Robinson, F., et al. (2020). Murray-Darling Basin Environmental Water Knowledge and Research Project: Waterbirds Theme Research Report.

OEH, N. (2012). Macquarie Marshes Ramsar site: Ecological character description Macquarie Marshes Nature Reserve and U-block components. Retrieved from

Reid, J. R., Colloff, M. J., Arthur, A. D., et al. (2013). Influence of catchment condition and water resource development on waterbird assemblages in the Murray-Darling Basin, Australia. Biological Conservation, 165, 25-34.

Roberts, J., \& Marston, F. (2011). Water Regime forWetland and Floodplain Plants: A Source Book for the Murray-Darling Basin. Canberra: National Water Commission.

Rogers, K., \& Ralph, T. J. (2010). Floodplain wetland biota in the Murray-Darling Basin: water and habitat requirements: CSIRO publishing.

Runge, C. A., Watson, J. E., Butchart, S. H., et al. (2015). Protected areas and global conservation of migratory birds. Science, 350(6265), 1255-1258.

Sandi, S. G., Saco, P. M., Rodriguez, J. F., et al. (2020). Patch organization and resilience of dryland wetlands. Science of The Total Environment, 726, 138581. doi:https://doi.org/10.1016/j.scitotenv.2020.138581

Sandi, S. G., Saco, P. M., Saintilan, N., et al. (2019). Detecting inundation thresholds for dryland wetland vulnerability. Advances in Water Resources, 128, 168-182. doi:https://doi.org/10.1016/j.advwatres.2019.04.016

Stolen, E. D., Breininger, D. R., \& Frederick, P. C. (2004). Using waterbirds as indicators in estuarine systems: successes and perils. In Estuarine indicators (pp. 431-444): CRC Press.

Webb, J. A., Wallis, E. M., \& Stewardson, M. J. (2012). A systematic review of published evidence linking wetland plants to water regime components. Aquatic Botany, 103, 1-14. doi:https://doi.org/10.1016/j.aquabot.2012.06.003

Wen, L., Macdonald, R., Morrison, T., et al. (2013). From hydrodynamic to hydrological modelling: Investigating longterm hydrological regimes of key wetlands in the Macquarie Marshes, a semi-arid lowland floodplain in Australia. Journal of Hydrology, 500, 45-61. doi:https://doi.org/10.1016/j.jhydrol.2013.07.015

Wilson, R. (1992). Vegetation map of the Macquarie Marshes. NSW National Parks and Wildlife Service: Sydney, NSW, Australia.

Xi, Y., Peng, S., Ciais, P., et al. (2021). Future impacts of climate change on inland Ramsar wetlands. Nature Climate Change, 11(1), 45-51. doi:10.1038/s41558-020-00942-2

Yu, L., García, A., Chivas, A. R., et al. (2015). Ecological change in fragile floodplain wetland ecosystems, natural vs human influence: The Macquarie Marshes of eastern Australia. Aquatic Botany, 120, 39-50. doi:https://doi.org/10.1016/j.aquabot.2014.07.002

Zou, Y., Liu, J., Yang, X., et al. (2014). Impact of coastal wetland restoration strategies in the chongming dongtan wetlands, China: waterbird community composition as an indicator. ACTA ZOOLOGICA HUNGARICA, 60(2), 185-198. 